\title{
O uso das mídias sociais pelo governador do estado de Goiás: estratégia de marketing político ou comunicação pública?
}

Use of the social media by the governor of Goiás:

a marketing strategy or public communication?

El uso de los medios sociales por el gobernador del estado de Goiás: ¿estrategia de marketing o comunicación pública?

Eva Márcia Arantes Ostrosky Ribeiro

- Mestre em Comunicação pela Universidade Federal de Goiás (UFG)

- Especialista em Marketing pela Fundação Getúlio Vargas (FGV)

- Bacharel em Comunicação Social - Relações Públicas pela UFG

- E-mail: eva_arantes@hotmail.com

Tiago Mainieri

- Pós-doutor em Comunicação pela Escola de Comunicação da Universidade Federal do Rio de Janeiro (ECO-UFRJ)

- Doutor em Ciências da Comunicação pela Escola de Comunicações e Artes da Universidade de São Paulo (ECA-USP), com período sanduíche na Universidade da Flórida e na Universidad Autónoma de Barcelona

- Mestre em Engenharia de Produção pelo Centro de Tecnologia da Universidade Federal de Santa Maria (CT-UFSM)

- Bacharel em Comunicação Social pela UFSM

- Pesquisador do Laboratório de Leitura Crítica da Mídia da Faculdade de Informação e Comunicação da Universidade Federal de Goiás (FIC-UFG)

- Docente do Programa de Pós-Graduação em Comunicação (PPGCom) da UFG

- E-mail: tiagomainieri@gmail.com 


\section{Resumo}

Este artigo é fruto de uma pesquisa de mestrado, que tem como intuito reconhecer se as mídias sociais podem ser um locus para o exercício da comunicação pública. Para isso, apresentamos resultados de um estudo de caso do twitter do governador de Goiás, Marconi Perillo. Com este estudo, pretende-se lançar algumas luzes sobre a discussão e o debate desse tema considerado nodal e recente na área da comunicação.

\section{PALAVRAS-CHAVE: GOVERNO DE GOIÁS• MÍDIAS SOCIAIS •TWITTER・COMUNICAÇÃO PÚBLICA.}

\section{Abstract}

This article reflects a graduate research the main objective of which is a study whether the social media could be a space for practice of public communication. For this we present the results of a case study of the Twitter of the governor of Goiás, Marconi Perillo. With this study one intends to highlight the discussion and debate of this theme that is considered to be nodal and recent in the area of communication.

\section{KEYWORDS: GOVERNMENT OF GOIÁS•SOCIAL MEDIA・TWITTER・PUBLIC COMMUNICATION.}

\section{Resumen}

Este artículo es fruto de una investigación de maestría, que tiene como objetivo reconocer si los medios sociales pueden ser un locus para el ejercicio de la comunicación pública. Por eso, presentamos resultados de un estudio de caso del twitterdel gobernador de Goiás, Marconi Perillo. Con el estudio, buscamos lanzar algunas luces para el debate y la discusión de ese tema considerado nodular y reciente para el área de la comunicación. 
ara iniciarmos a discussão sobre o uso das mídias sociais, especificamente o Twitter, no governo do estado de Goiás, torna-se importante ressaltar conceitos teóricos dessas mídias e, também, contextualizar a presente pesquisa.

A internet provoca uma mudança na forma de as pessoas se comunicarem, sobretudo a partir da não-existência do papel fixo e predeterminado de emissores e receptores de conteúdo. Esse ponto, aliás, talvez seja a maior mudança provocada pela virtualidade, algo que retira das mídias massivas tradicionais, como televisão, rádio e jornal, a primazia de serem únicas transmissoras de informação. Pierre Lévy (2010, p. 13) argumenta que,

enquanto as mídias de massa, desde a tipografia até a televisão, funcionavam a partir de um centro emissor para uma multiplicidade receptora na periferia, os novos meios de comunicação social interativos funcionam de muitos para muitos em um espaço descentralizado.

Em especial, com o advento da internet, as pessoas se relacionam, simultaneamente, emitindo e recebendo informações, reconfigurando os processos comunicacionais.

Massimo Di Felice (2008), na obra Do público para as redes, ressalta que a humanidade passou por três grandes revoluções comunicativas ao longo da história. Para ele, essas revoluções estão ligadas ao surgimento da escrita, da impressão e da cultura de massa. Assim, a primeira revolução é marcada pela passagem da sociedade oral para a sociedade da escrita, no século V a.C., no Oriente Médio. Já no século XV, com o surgimento da impressão, iniciou-se a segunda revolução. Entre os séculos XIX e XX, acontece a terceira revolução, marcada pela cultura de massa, caracterizada pelos meios de comunicação.

Di Felice sustenta que no decorrer de cada uma dessas revoluções não foram introduzidas apenas novas formas de se comunicar, mas sim novas formas de interação social. Nos dias atuais, a humanidade estaria vivenciando o que o autor denomina como uma quarta revolução, implementada pelas tecnologias digitais. 0 fato é que, nessa perspectiva, 0 advento das mídias digitais altera "a forma de comunicar, fornecendo a cada sujeito o mesmo poder de comunicação" (Di Felice, 2008, p. 24).

A grande mudança proporcionada por essa "quarta revolução" é a relação estabelecida entre o emissor e o receptor, a qual altera profundamente a forma de as pessoas se comunicarem. Diante dessas mudanças, Di Felice (2008, p. 23) diz que,

pela primeira vez na história da humanidade, a comunicação se torna um processo de fluxo em que as velhas distinções entre emissor, meio e receptor se confundem e se trocam até estabelecer outras formas e outras dinâmicas de interação, impossíveis de serem representadas segundo os modelos dos paradigmas comunicativos tradicionais. (Shannon-Weaver, Katz-Lazarsfeld e Eco-Fabbri, apud Di Felice, 2008, p. 23).

Assim, observa-se que o surgimento das mídias sociais acarreta mudanças nas formas de se pensar e de se fazer a comunicação e, consequentemente, nas formas da interação social.

Pierre Lévy e André Lemos (2010) também discutem como o surgimento das mídias sociais ou de sistemas pós-massivos modifica a forma de comunicação baseada em emissores e receptores, na qual cada um desses sujeitos tem papeis bem definidos. Podemos entender, a partir do pensamento dos autores, que com as mídias sociais todos são ao mesmo tempo emissores e receptores de conteúdo e informação, e essa mudança altera profundamente as formas de interação social. 


\section{O USO DO TWITTER PELO GOVERNADOR DO ESTADO DE GOIÁS, MARCONI PERILLO}

Para fins de contextualização, o presente texto é fruto de uma dissertação de mestrado' defendida em 2012, da qual se obtiveram os dados deste trabalho. 0 objetivo principal do estudo foi entender o perfil do twitter do governador de Goiás, Marconi Perillo, e verificar se o mesmo pode ser considerado um instrumento de comunicação pública. Para isso, foi realizada uma pesquisa com o governador, com sua equipe de mídias sociais e com uma amostra de seus seguidores do twitter.

Apoiamo-nos em Lévy (2010, p. 12), para quem, por meio de aplicações como o "Twitter (microblog contínuo), a relação social pelo ciberespaço torna-se quase permanente". 0 autor destaca ainda que "a nova comunicação pública é polarizada por pessoas que fornecem, ao mesmo tempo, os conteúdos, a crítica, a filtragem e se organizam, elas mesmas, em redes de troca e colaboração" (Lévy, 2010, p. 13).

A pesquisa realizada sinaliza alguns caminhos que nos levam a refletir sobre os usos e as possibilidades de uso das mídias sociais digitais na consolidação da comunicação pública.

\section{O CAMINHO DA COMUNICAÇÃO PÚBLICA}

Antes da exposição dos dados, discutimos, brevemente, o conceito de comunicação pública. Torna-se importante enfatizar que o conceito de comunicação pública é polissêmico. Antes de chegar a um posicionamento sobre o assunto, refletimos sobre 0 conceito de comunicação política e governamental, baseando-nos, para tanto, em Elizabeth Brandão (2007).

O fato é que entendemos que a comunicação governamental visa à prestação de contas de um determinado governo para a sociedade. Já a comunicação política associa essa comunicação ao marketing político, utilizando para isso estratégias de comunicação persuasiva e de convencimento.

Para definir o conceito de comunicação pública, valemo-nos de diferentes autores, tais como Elizabeth Brandão (2007), Heloiza Matos (2009), Jorge Duarte e outros (2007), cuja base teórica tem como fundamento o pensamento de Pierre Zémor (1995)².

Em síntese, de acordo com Zémor (1995, p. 5), a função precípua da comunicação pública é a informação, mas ela deve ir além do mero processo informativo. 0 autor ressalta cinco categorias para identificar a comunicação pública:

1. Responder à obrigação que têm as instituições públicas de levar informação a seus públicos;

2. Estabelecer a relação e o diálogo de forma a desempenhar o papel que cabe aos poderes públicos, bem como para permitir que o serviço público atenda às necessidades do cidadão de maneira mais precisa;

3. Apresentar e promover cada um dos serviços oferecidos pela administração pública;

4. Tornar conhecidas as instituições a elas mesmas, tanto por meio da comunicação interna quanto da externa;

5. Desenvolver campanhas de informação e ações de comunicação de interesse geral. 
Através dessas categorias e da visão de outros autores, também abordados neste estudo, iremos analisar as respostas obtidas nos questionários, a fim de perceber se o governador estabelece ou não uma comunicação pública com seus seguidores por meio de seu twitter.

\section{OS ASPECTOS METODOLÓGICOS DA PESQUISA}

Para a realização deste estudo, foi utilizado como um dos métodos de pesquisa a abordagem qualitativa, através de entrevistas feitas com o governador Marconi Perillo e sua equipe de mídias sociais. Essas fontes para a entrevista foram selecionadas seguindo critérios de conhecimento e de vivência do assunto que tínhamos como objeto de pesquisa: o twitter do governador. Diante da impossibilidade de se fazer a entrevista pessoalmente, conforme descrevemos, as entrevistas foram realizadas através de um questionário aberto, enviado via e-mail. 0 principal objetivo dessas entrevistas era perceber como foi planejado o twitter do governador e compreender como essa mídia é utilizada para aproximar o governador do cidadão.

Inicialmente cabe caracterizarmos o Twitter como uma rede de informação em tempo real que conecta os indivíduos às informações instantâneas e atualizadas. 0 Twitter é composto por informações compactadas em até 140 caracteres, chamadas tweets(tuítes, segundo terminologia já em uso no português). Apesar da limitação de caracteres é possível fornecer informações adicionais. Dessa forma, conteúdos como vídeos, links etc. podem ser agregados. De acordo com o próprio site do Twitter ${ }^{3}$, ele

conecta empresas aos seus clientes em tempo real (...) para compartilhar informações de forma rápida com as pessoas interessadas em seus produtos e serviços, para coletar sugestões e informações do mercado em tempo real, e construir relacionamentos com clientes, parceiros e pessoas influentes.

O fenômeno das mídias sociais digitais vem sendo analisado por autores como Raquel Recuero. Uma das principais características das mídias sociais, destacada por ela, é a grande capacidade de difusão de informações dessas redes. "Muitas dessas informações são difundidas de forma quase epidêmica, alcançando grandes proporções tanto on-line quanto off-line" (Recuero, 2009, p. 116).

Após as entrevistas com o governador e a equipe de mídias sociais, também foram realizadas entrevistas fechadas por meio de questionário com seguidores do twitter do governador. 0 propósito foi perceber se há interação e diálogo entre governador e seguidor. A relevância desse questionário diz respeito à feitura do cruzamento das informações obtidas nas entrevistas com a tabulação dos dados obtidos por meio dos questionários.

Para se realizar esse questionário com os seguidores do twitter do governador Marconi Perillo, elaborou-se um perfil da pesquisa no twitter para facilitar o envio dos questionários, em formato google.doc. A população ${ }^{4}$ para realização do cálculo amostral foi de 22.227 (vinte e dois mil e duzentos e vinte e sete) seguidores, sendo que essa quantidade foi retirada do twitterna data do dia 31 de março de 2011.

\section{APRESENTAÇÃO E ANÁLISE DOS RESULTADOS}

Na apresentação e análise dos resultados da pesquisa realizada, fizemos o cruzamento das informações obtidas por meio das entrevistas com o governador e a equipe de mídias sociais com a opinião dos seguidores. 
De acordo com o questionário feito com a assessora de mídias sociais, o objetivo maior para o governador Marconi Perillo estar presente nas mídias sociais é o de aproximar o governo do cidadão, a partir de uma comunicação dialógica e de mão dupla. Nas palavras da assessora, o governador tem um twitter "como forma de interação e aproximação do cidadão com o governador". Também perguntamos aos seguidores por quais motivos eles têm twitter. Ea grande maioria das pessoas que respondeu salientou que o maior motivo de estar presente nessa mídia é devido ao acesso fácil a informações, de todos os gêneros, e para interação.

Além disso, foi salientado o fato de o twitter ser uma mídia que possibilita ao usuário transmitir informações. Desse modo, tanto para o governador quanto para sua assessora e seus seguidores, estar presente nessa mídia tem como principal motivo a interação entre pessoas. Assim, reforça-se a percepção de Recuero (2009) ao ressaltar que essas mídias sociais constituem um espaço para expor e publicizar a rede dos atores envolvidos, muitas delas exigindo a criação de um perfil que permita a interação com outras pessoas, como no caso do Twitter. Entretanto, apesar das possibilidades de interação, o uso das mídias sociais digitais revela ainda a prevalência de uma lógica transmissionista, conforme observamos no próprio exemplo em análise.

Outra pergunta feita à assessora foi em relação às respostas dadas aos seguidores para os questionamentos. "São respondidos pelo próprio governador e encaminhados às nossas ferramentas. Assim, estabelecemos um diálogo com nossos seguidores", respondeu ela. Porém, quando perguntamos ao governador se existe uma seleção para responder aos questionamentos dos seus seguidores, ele disse que não e ressaltou que, "pela impossibilidade de responder todos, o perfil @marconi_equipe responde aos usuários".

Como se pode ver, a assessora disse que todos os questionamentos são respondidos pelo governador e salientou que somente são encaminhadas as ferramentas da equipe. Já o governador admite que, pela impossibilidade de responder a todos, o perfil mantido pela equipe responde aos usuários. Percebe-se, nessas respostas, que o governador conta com a intermediação da sua equipe para responder os questionamentos que lhe são feitos, no seu perfil pessoal. Outro dado que é importante de ser salientado diz respeito à informação obtida pelo site TweetStats ${ }^{5}$, que ressalta que apenas $29,22 \%$ de todas as postagens feitas pelo governador, em seu perfil, estão relacionadas a respostas dadas ou replies. É importante salientar que esses replies têm maior concentração para perfis mantidos por um jornalista, um cantor/compositor e um estrategista político/ radialista. Não aparecem, na listagem obtida por esse site, respostas dadas para um perfil mantido por um cidadão comum.

Recuero (2009) destaca alguns valores relacionados às redes sociais e a sua apropriação pelos atores, sejam organizações ou os indivíduos com os quais elas interagem, entre eles o aumento da visibilidade social, a reputação, a popularidade e a autoridade referindo-se ao poder de influência. Desse modo, a partir do site que analisa perfis do twitter, o TweetRank no quesito da influência do perfil pessoal do governador, constatamos uma nota muito baixa de influência (24,29), e, por essa razão, ele nem aparece na classificação nacional do ranking feito pelo site. Vale lembrar que a nota de influência está relacionada à interação entre o usuário do perfil e seus seguidores.

É importante destacar também que apenas $24 \%$ dos seguidores que responderam esse questionário são seguidos pelo governador. Na verdade, esse dado confirma as informações de influência retiradas desse site, pois percebemos que $74 \%$ dos seguidores não são seguidos pelo governador.

Com esses dados, nota-se também que muitos seguidores não obtêm respostas para seus questionamentos, mesmo quando o governador e a assessora afirmam que todos os questionamentos são respondidos. Dessa forma, contraria-se um dos 
fundamentos da comunicação pública; conforme postula Zémor (1995), informar constitui-se em um primeiro passo para a efetivação da comunicação pública.

A assessora ressaltou, também, que o twitter possibilita uma relação on-line e permanente entre governador e cidadão. $\mathrm{E}$ afirmou que a intenção de ter o governador presente nessa mídia "é dar transparência, abrir canais de comunicação diretos de comunicação do governo com a sociedade".

Também perguntamos ao governador Marconi Perillo o objetivo de ter um perfil no Twitter, e, como já ressaltado pela assessora, ele afirma que é pelo fato de essa mídia proporcionar um canal direto de comunicação e interação com o cidadão - segundo suas palavras, "uma via de mão dupla com a sociedade".

De acordo com essas respostas dadas pela assessora e pelo governador, entendemos que estar presente nas mídias sociais abre canais de comunicação entre governador e cidadão.

Conforme aponta Zémor (1995) em suas categorias, a comunicação pública deve transmitir informação aos públicos e estabelecer relação e diálogo, de forma a se desempenhar o papel que cabe aos poderes públicos. Tanto o governador quanto a assessoria sempre ressaltaram a capacidade que o Twitter tem de gerar diálogos e interação entre governo e cidadão. Assim, a comunicação estabelecida via essa mídia, segundo ambos, vai além da mera emissão de informação e busca uma comunicação dialógica e interativa.

Outracaracterística apontada por PierreZémor, em relaçãoà comunicação pública, diz respeitoànecessidade de sedesenvolverem campanhas de informação e ações de comunicação de interesse geral. Nesse sentido, quando perguntado à assessora como são selecionados os assuntos tratados via Twitter, ela respondeu que não existe seleção: "desde que seja relevante para o público".

Na verdade, assuntos de interesse público são característicos da comunicação pública e, como aponta Graça França Monteiro (2007, p. 40), é necessário que as mensagens da comunicação pública "sejam fruto do debate público e propiciem o debate público". Pensando nessa questão, percebe-se que as mensagens postadas no twitter do governador, de acordo com suas respostas, visam ao interesse público.

Quando perguntado ao governador como são definidos os temas a serem tratados no seu twitter, ele afirmou: através do perfil pessoal, "converso com as pessoas, respondo algumas perguntas endereçadas a mim, falo de assuntos do governo e também da minha vida pessoal". É importante, mais uma vez, salientar que o governador tem mais dois perfis no Twitter mantidos pela assessoria, cujo intuito é transmitir informações do governo.

Analisando o perfil pessoal do governador, observa-se que há a intenção de dialogar com algumas pessoas e também de responder algumas perguntas. Ou seja, o governador responde a quem deseja, fato esse também demonstrado quando se vê a maior quantidade de replies dados pelo seu perfil, por meio do site TweetStats.

A partir desses dados, entende-se que o governador usa essa mídia para transmitir informações e postar mensagens que nem sempre dizem respeito à coletividade. Por outro lado, vê-se que os perfis mantidos pela assessoria divulgam ações do governo, tais como eventos, agenda etc., ou seja, têm como intuito divulgar ações do governo, informando o cidadão sobre o que o governador faz e como está seu governo. 
Segundo Pierre Zémor (1995), essa seria a função fundamental da comunicação pública, uma vez que ela deve ir além da mera informação. É importante deixar claro que a comunicação informativa não estabelece uma comunicação de mão dupla, como enfatiza o governador em suas respostas sobre o objetivo de ter um perfil no Twitter. Mas entende-se que 0 twitter do governador Marconi Perillo abre canais de comunicação para o cidadão chegar ao governante, uma característica importante da comunicação pública, como também aponta Zémor (1995).

No questionário para os seguidores, perguntamos se eles já tinham enviado algum questionamento ao governador. E tivemos como resposta que $70 \%$ nunca enviaram nenhuma pergunta ao governador; apenas $26 \%$ responderam que sim. Diante disso, vê-se que o cidadão nem sempre usa o Twitter para se aproximar do governante. Ele tem o canal, mas nem sempre o usa para essa finalidade.

Aos seguidores que responderam que nunca postaram nada para o governador perguntamos o motivo. E 44\% responderam que nunca tiveram interesse. Diante disso, o que vemos é que o canal de comunicação para aproximar o cidadão do governante foi criado, mas os seguidores, em sua maioria, nem sempre têm interesse em um diálogo.

Para a questão acerca da postagem para o governador, demos como alternativa a opção "Outros", que foi assinalada por $28 \%$ das respostas. Nessa categoria, as respostas dadas foram que ainda não tinham algo a dizer ao governador ou não tinham interesse em enviar um questionamento; que seguiam o governador fazia pouco tempo e por esse motivo nunca mandaram um questionamento; além disso, também foi ressaltado que nunca houve a postagem de um questionamento porque não se acreditava que o governador o responderia pessoalmente ou mesmo que ele seria respondido. Nesse sentido, o seguidor percebe que nem sempre é o governador que responde aos questionamentos feitos ou que não terá resposta. Isso mostra que nem sempre seu twitteré percebido pelo seguidor como um locus de diálogo, sem a presença de intermediários, como sempre foi enfatizado pelo governador. Diante disso, torna-se importante rever o conceito de mensagens dotadas de interesse público, como apontado pela assessora.

Cabe ressaltar que dos seguidores que postaram algo para o governador, $26 \%$ dos que responderam o questionário têm interesse em discutir algum assunto relacionado ao governo e fazer cobranças via Twitter.

Pode-se entender com essa questão que os seguidores, quando postam algo para o governador (uma minoria das respostas obtidas), usam o Twitter como ferramenta para se aproximar do governo, seja através de questionamentos com dúvidas e cobranças ou também para parabenizar o governador por alguma ação feita. Percebe-se, assim, que, quando julga necessário, o cidadão utiliza o Twitter para ter acesso ao governador.

Outra pergunta feita apenas para os que enviaram algum questionamento para o governador, estava relacionada ao recebimento de uma resposta por parte do governo. Deles, $62 \%$ assinalaram que não obtiveram respostas para seus questionamentos. Esse dado contradiz o que a assessora e o governador ressaltaram em suas respostas, a saber: "faço o possível para responder todos os questionamentos. E pela impossibilidade de responder todos, o perfil @marconi_equipe responde aos usuários". Na verdade, tal dado confirma as informações obtidas nos sites que analisam o perfil mantido pelo governador, conforme já mencionado.

Entende-se que, para haver uma comunicação pública, é necessário haver uma comunicação dialógica. E, segundo esse dado, nem sempre há diálogo, pois muitas vezes o cidadão fica sem respostas para seus questionamentos ou recebe respostas que não o satisfazem - e é interessante notar que o governador e a assessora sempre ressaltaram que o intuito maior em estar presente nessa mídia é para estabelecer uma comunicação de mão dupla com o cidadão. 
Por fim, perguntamos a todos os seguidores o que eles acham das mensagens postadas no twitter do governador. E 41\% responderam que as mensagens visam transmitir informações do governo, sendo que $26 \%$ responderam que as mensagens servem para aproximar o governador do seguidor e 15\% salientaram o fato de elas visarem ao estabelecimento de um diálogo com os seguidores.

\section{CONSIDERAÇÕES FINAIS}

Conforme as respostas obtidas nos questionários, percebe-se que, no que tange ao twitter do governador, os assuntos são tratados mais com o fim de estabelecer um canal de informação para o cidadão do que para discutir e debater algo de relevância e de interesse público. E, quando existe um questionamento por parte do seguidor, há a intermediação da assessoria do governador para respondê-lo. Nem todos os seguidores obtêm respostas; quando conseguem uma resposta, alguns a consideram como algo genérico ou a veem como algo automático.

A grande mudança proporcionada pelas mídias sociais é estabelecer uma comunicação sem intermediários, onde todos podem ser receptores e emissores de conteúdo, constatação já feita por autores como Lévy, Lemos, Di Felice e Recuero. Nesse sentido, entendemos que no twitter do governador Marconi Perillo ainda existe a figura do intermediário, que é a sua assessoria, composta por quinze profissionais, entre jornalistas, fotógrafos, designers, cinegrafistas e assistentes. Percebese que se trata de uma equipe bem qualificada para realizar essa intermediação entre governador e seguidor.

Um fato inegável é que existe o canal de comunicação. E vemos que o seguidor, a fim de se aproximar do governante, pode fazê-lo de forma direta. Ou seja, o cidadão, através do twitter tem um acesso mais fácil ao governador e às ações de seu governo. Mas 70\% dos seguidores nunca postaram nada para o governador, conforme dados já apontados. E, desses, 44\% responderam que nunca o fizeram, por falta de interesse.

Vê-se, assim, que também falta muito para os usuários das mídias sociais, neste caso o Twitter, perceberem que esta é uma mídia que possibilita a aproximação com o governante e que, através dela, pode-se estabelecer um canal de comunicação pública.

Com os dados que colhemos, percebemos que, teoricamente, tanto o governador quanto a assessora de mídias sociais entendem o papel e a importância das mídias sociais. Porém, o uso que fazem do Twitter ainda é predominantemente para divulgar ações do governo, reforçando a lógica "transmissionista" questionada anteriormente.

Como Wilson Gomes (2005) aponta, o que se vê é que

o estado é um provedor de informações políticas. A sua comunicação on-line com o público ainda é majoritariamente a produção de materiais destinados a produzir, unidirecionalmente, opinião pública favorável ou, no melhor dos casos, a prestação de informações básicas sobre o funcionamento do estado ${ }^{7}$.

0 que se pode observar é que o Estado ainda busca divulgar informações políticas e relativas ao governo com o intuito de buscar uma opinião favorável do seu governo e, consequentemente, conquistar votos, algo que tem respaldo nos dados obtidos e interpretados nesta pesquisa.

7 Acessado em <http://www.gepicc.ufba.br/enlepicc/pdf/WilsonGomes.pdf> 
Mesmo nas mídias sociais que possuem características que podem facilitar a aproximação de cidadão e governante, ainda predomina uma comunicação política, informativa, e não um diálogo que visa discutir assuntos de interesses públicos e coletivos.

O fato é que até o próprio seguidor nem sempre tem essa noção de participação e de estabelecer um diálogo com o governante através dessa mídia, conforme observamos a partir das respostas no questionário realizado com esse público.

Pode-se afirmar que o twitter do governador Marconi Perillo tem um caráter predominantemente informativo, diferente do que é afirmado em suas respostas. As informações têm como objetivo esclarecer a sociedade a respeito das ações e práticas de seu governo. De todo modo, é importante ressaltar, nesse sentido, que gerar informações do governo é um primeiro passo para se estabelecer uma comunicação pública, dialógica, como aponta Pierre Zémor (1995).

Assim, concluímos que o twitter do governador Marconi Perillo é um espaço para uma comunicação mais próxima com 0 cidadão, porém ainda não possibilita uma comunicação essencialmente dialógica e com espaço para debater assuntos de relevância pública, como aponta característica da comunicação pública, ressaltada por diferentes autores.

De fato, percebemos que o twitter, enquanto mídia social, tem a possibilidade de proporcionar uma comunicação verdadeiramente pública, pois é um novo canal de comunicação entre governante e cidadão - e vice-versa. Entretanto, o efeito da mutação da esfera pública, conforme apontado por Lévy (2010), ainda não se efetiva plenamente, ou seja, a pressão exercida sobre as administrações públicas e os governantes por mais transparência, abertura e diálogo nem sempre encontra eco nessas estruturas.

Nesse sentido, vemos que o twitter do governador Marconi Perillo é um locus voltado à transmissão de informações do governo, a partir da atuação de uma equipe bem preparada para garantir essa transmissão diária de informações sobre as realizações governamentais. Portanto, está mais afastado do ideal de ser uma ferramenta para estabelecer uma interação realmente pública com o seguidor, como aponta Recuero (2009) ao analisar as possibilidades das mídias sociais.

0 fato é que ainda temos muito que amadurecer, tanto por parte do governo, no sentido de realmente fazer dessa mídia um espaço para diálogos e discussões, quanto por parte também do seguidor, que pode vir a usar essa mídia para dialogar de forma profícua com o poder público.

\section{REFERÊNCIAS}

BRANDA0, Elizabeth Pazito. Conceito de comunicação pública. In: DUARTE, Jorge (Org.). Comunicação pública: estado, mercado, sociedade e interesse público. São Paulo: Atlas, 2007.

DI FELICE, Massimo (Org.). Do público para as redes. a comunicação digital e as novas formas de participação social. São Caetano do Sul, SP: Difusão, 2008.

DUARTE, Jorge (Org.). Comunicação pública: estado, governo, mercado, sociedade e interesse público. São Paulo: Atlas, 2007. Instrumento de comunicação pública. In: DUARTE, Jorge (Org.). Comunicação pública: estado, mercado, sociedade e interesse público. São Paulo: Atlas, 2007. 
GOMES, Wilson. Internet e participação política em sociedades democráticas. In: ENCUENTRO LATINO AMERICANO DE ECONOMÍA POLÍTICA DE LA INFORMACIÓN, COMUNICACIÓN Y CULTURA, V, Salvador, Universidade Federal da Bahia, 9-11 de novembro de 2005. Disponível em: <http://www.gepicc.ufba.br/enlepicc/pdf/WilsonGomes.pdf>.

LEMOS, André; LÉVY, Pierre. O futuro da internet. em direção a uma ciberdemocracia. São Paulo: Paulus, 2010.

LÉVY, Pierre. Prefácio à edição brasileira - A mutação inacabada da esfera pública. In: LEMOS, André; LÉVY, Pierre. O futuro da internet. em direção a uma ciberdemocracia. São Paulo: Paulus, 2010.

MATOS, Heloiza. Capital social e comunicação: interfaces e articulações. São Paulo: Summus, 2009.

MONTEIRO, Graça França. A singularidade da comunicação pública. In: DUARTE, Jorge (Org.). Comunicação pública: estado, mercado, sociedade e interesse público. São Paulo: Atlas, 2007.

RECUERO, Raquel. Redes sociais na internet. Porto Alegre: Sulina, 2009.

RIBEIRO, Eva Márcia Arantes Ostrosky. A comunicação pública como processo para o exercício da cidadania a partir das mídias sociais. Estudo de caso: twitter Marconi Perillo. Dissertação (Mestrado em Comunicação) - PPGCom/UFG, 2012.

ZÉMOR, Pierre. La communication publique. Paris: PUF, 1995. Tradução livre e resumida de Elizabeth Brandão. Disponível em: <http://www.ucb.br/comsocial/mba/ComunicacaoPublicaPierreZemor_traducao.pdf>.

Artigo recebido em 139.03.2015 e aprovado em 01.06.2015. 